\title{
A Comparative Study of $0.5 \%$ Ropivacaine vs $0.25 \%$ Bupivacaine in Transverse Abdominis Plane Block for Post Operative Analgesia in Patients Undergoing Abdominal Surgeries
}

\author{
Authors \\ Preethi Vaddi ${ }^{*}$, Kalyan Chakravarthy $\mathbf{P}^{2}$, Hemnath Babu Kotla ${ }^{3}$, \\ Rekha P A L ${ }^{4}$, Sreevidya Ramineedi ${ }^{5}$ \\ ${ }^{1}$ Postgraduate, Department of Anaesthesiology, GEMS. \\ ${ }^{2}$ Professor, Department of Anaesthesiology, GEMS. \\ ${ }^{3}$ Associate Professor, Department of Anaesthesiology, GEMS. \\ ${ }^{4,5}$ Postgraduate, GEMS. \\ *Corresponding Author \\ Preethi Vaddi \\ Postgraduate, Department of Anaesthesiology, GEMS
}

\begin{abstract}
Aims and Objectives: Transversus abdominis plane block is a regional anaesthesia technique. It provides analgesia after abdominal surgery particularly where parietal wall pain forms major component of pain. It allows sensory blockade of lower abdominal wall skin and muscles via local anaesthetic deposition above transverses abdominus muscle. We evaluated the efficacy of TAP block with Ropivacaine and Bupivacaine for post operative analgesia in abdominal surgery, a double blind, prospective randomized controlled trial.
\end{abstract}

Method: 50 patients undergoing elective abdominal surgeries under general anaesthesia were randomized to undergo Tap block with Ropivacaine $(n=25)$ or Bupivacaine $(n=25)$.Tap block was performed at the end of surgery using $20 \mathrm{ml}$ of $0.5 \%$ Ropivacaine or $0.25 \%$ Bupivacaine each side. Each patient was assessed postoperatively by a blinded observer at 30mins, 1, 3, 6, 12 \& 24 hrs in ward.

Result: The results in both groups were comparable clinically as well as statistically.

Conclusion: we conclude that 0.5\% Ropivacaine provided longer duration of analgesia than $0.25 \%$ Bupivacaine when used in TAP block for patients undergoing abdominal surgery. Both drugs have a good safety profile. Both drugs show outstanding clinical utility in terms of reliability and effective analgesia.

Keywords: TAPB, Bupivacaine, Ropivacaine, post operative analgesia, general anaesthesia,

\section{Introduction}

Postoperative pain is an acute pain which starts with surgical trauma and ends with tissue healing. In spite of advances in the knowledge, skill and sophisticated technology, many patients continue to experience considerable discomfort during postoperative period due to pain. ${ }^{[1]}$ There is growing evidence that acute postoperative events may have long-term consequences such as postoperative myocardial ischemia, infarction and development of chronic pain syndromes. ${ }^{[2]}$

Postoperative analgesia can be achieved by the use of oral or parenteral analgesics, peripheral nerve 
blocks, neuraxial blocks with local anaesthetics, intrathecal opioids, adjunctive techniques such as Transcutaneous Electrical Nerve Stimulation (TENS) and physical therapy. ${ }^{[3]}$

Pain experienced by patients after abdominal surgery is mainly derived from the anterior abdominal wall incision. ${ }^{[3]}$ Therefore provision of postoperative analgesia after abdominal surgery dominantly from skin incision sites, creation of Pneumoperitoneum and trauma created by surgery by blocking the sensory nerve supply to the anterior abdominal wall appears to be a promising approach. ${ }^{[4][2]}$ Although laparoscopic surgeries result in less pain than open surgeries, still the pain arises pre itself. ${ }^{[3]}$

Apart from providing post operative pain relief, regional anaesthetic techniques improve patient recovery by preventing the neuroendocrine responses to surgery. ${ }^{[1]}$

Transversus abdominis plane (TAP) block is one of the regional analgesic techniques reducing the postoperative pain of abdominal surgeries. ${ }^{[5]}$ Based on anatomic studies, previously, the lumbar triangle of Petit was used as an access point. A loss of resistance technique was used to locate the transverses abdominis plane. ${ }^{[6]}$ Correct localization of the plane was found to be difficult and imprecise in blind technique, especially in elderly and obese patients. $^{[7]}$

To overcome this, ultrasound guidance is being increasingly used to locate the Transversus abdominis plane. ${ }^{[5]}$ Ultrasound based studies have shown their superiority and accuracy over the blind abdominal wall injections. ${ }^{[7]}$

Various local anaesthetic agents have been used to provide effective and adequate postoperative analgesia. The new long-acting amino-amide local anaesthetic, ropivacaine, an S- enantiomer of bupivacaine has higher anaesthetic potency with long duration of action and less toxicity profile as compared to Bupivacaine ${ }^{[8]}$. It is 2-3 times less lipid soluble and has a smaller volume of distribution, greater clearance, and shorter elimination half-life than Bupivacaine in humans. The two drugs have a similar pKa and plasma protein-binding. ${ }^{[9]}$
The present study is aimed at comparative evaluation and relative efficacy of $0.5 \%$ Ropivacaine and $0.25 \%$ Bupivacaine in ultrasound guided TAP block for post operative analgesia in abdominal surgeries.

\section{Material and Methods}

The present study was conducted after obtaining approval by the hospital ethics committee, a written informed consent was obtained from 50 patients of either sex between 18-60 yrs of age belonging to ASA grade 1 \&2 scheduled for elective lower abdominal surgeries under general anaesthesia. The patients were randomly divided into two groups of 25 each- Group B receiving 0.25\% Bupivacaine, group $\mathrm{R}$ receiving $0.5 \%$ Ropivacaine. A prospective, randomized, double blinded comparative study was conducted for a period of 6 months in Department of Anaesthesiology, Great Eastern Medical School \& Hospital, Srikakulam.

\section{Inclusion Criteria}

1) ASA physical status I or II

2) Aged between 18 to $60 \mathrm{yrs}$

3) Body weight 50-75kgs (BMI >18.5 and < 25)

4) Patients undergoing elective abdominal surgeries under general anesthesia

5) Patients giving valid consent

\section{Exclusion Criteria}

1) Patients with history of sensitivity to local anesthetics

2) Patients with abnormal liver function, infection at injection site

3) Patients with clotting abnormalities

4) Patients who were not unable to interpret VAS before surgery

5) Pregnant women

\section{Preoperative Assessment and Premedication}

Every patient underwent pre-anaesthetic check-up a day prior to surgery that includes detailed history, complete general physical and systemic examination and relevant investigations. They were explained about linear visual analog scale for pain 
(0 - no pain, 10 - worst imaginable pain) in their own vernacular language. All patients received adequate fasting orders preoperatively according to the surgery planned.

\section{Intraoperative Management}

The patient was shifted to the operating room and an intravenous access (18G) was established. Pulse rate (PR), non invasive blood pressure (NIBP), continuous electrocardiogram (ECG), respiratory rate (RR), end tidal carbon dioxide and arterial oxygen saturation ( $\mathrm{SpO} 2)$ were monitored using Multipara-monitors. Baseline readings were noted and monitored every 5 minute intervals for first 30 minutes of surgery and then every 15 minutes till the end of surgery.

\section{Induction of Anaesthesia}

All patients were premedicated with Inj. Glycopyrrolate $10 \mathrm{mcg} / \mathrm{kg} / \mathrm{iv}$ and Inj. Fentanyl 2 $\mathrm{mcg} / \mathrm{kg} / \mathrm{iv}$. They were preoxygenated with $100 \%$ oxygen for 3 mins. Intravenous induction was achieved with Propofol 2-2.5 mg/kg. After confirming the ability to ventilate the lungs, intravenous Vecuronium $0.1 \mathrm{mg} / \mathrm{kg}$ was used for neuromuscular blockade. Patients ventilation was assisted with $100 \%$ oxygen for 3 minutes, followed by laryngoscopy and orotracheal intubation was performed using either 7 or $7.5 \mathrm{~mm}$ internal diameter polyvinyl chloride cuffed orotracheal tube in women and either 8 or $8.5 \mathrm{~mm}$ internal diameter polyvinyl chloride cuffed orotracheal tube in men.

Maintainance of anaesthesia was done with sevoflurane1-1.2 MAC, 66\% N2O, and 33\% O2.

Inj Fentanyl $1 \mathrm{mcg} / \mathrm{kg}$ as needed to maintain intraoperative analgesia was given. Injection Paracetamol 1gm IV was given at the time of skin closure.

\section{At the end of surgery}

Hemodynamic parameters of the patient were noted and TAP block was administered

Group R (n=25): Patients in this group received $20 \mathrm{ml} 0.5 \%$ Ropivacaine on each side
Group B $(\mathbf{n}=\mathbf{2 5})$ : Patients in this group received $20 \mathrm{ml}$ of $0.25 \%$ Bupivacaine on each side.

Post block hemodynamic parameters of the patient were noted.

\section{After giving TAP block}

Oral suction was performed and reversal of neuromuscular blockade was done with Neostigmine $0.05 \mathrm{mg} / \mathrm{kg}$ and Glycopyrrolate 0.01 $\mathrm{mg} / \mathrm{kg}$ after confirming the return of neuromuscular function. Then patient was extubated and shifted to postoperative recovery ward.

In postoperative period, hemodynamic variables ,the presence and severity of pain was assessed systematically using Visual Analog Scale (VAS) at 30 minutes, $1 \mathrm{hr}$, $3 \mathrm{hrs}$, $6 \mathrm{hrs}, 12 \mathrm{hrs}$ and 24 hours from the time of TAP block. The VAS score $(0=$ no pain; $10=$ most severe pain) was recorded at rest.

Any patient with a VAS score of more than 3 received rescue analgesia with Inj.Tramadol $1 \mathrm{mg} / \mathrm{kg} / \mathrm{iv}$ in $100 \mathrm{ml}$ normal saline, with maximum of three doses over 24 hours. Patients were observed for symptoms of local anaesthesia toxicity and transient femoral nerve palsy.

\section{Results}

The following observations, including patients' preoperative hemodynamic parameters, the postoperative hemodynamic parameters, the pain scores using visual analogue score were recorded in a preformed proforma.

\section{Demographic Data}

\section{a) Age}

The patients had mean age (mean \pm SD) of $43.23 \pm 8.91$ and $40.97 \pm 9.98$ years in Group B and Group $\mathrm{R}$ respectively. The mean age of the patients in both the groups was comparable and the difference was statistically not significant. $(p>0.05)$

\section{b) Weight}

The mean body weight of patients (mean \pm SD) in group $\mathrm{B}$ and $\mathrm{R}$ was $60.7 \pm 8.0$ and $67.2 \pm 10.6 \mathrm{kgs}$ respectively. The body weight of patients in both the groups was comparable and statistically non significant. $(p>0.05)$ 


\section{c) Sex Ratio}

The male: female ratio in group B was 11: 14 as compared to $13: 12$ in group $\mathrm{R}$. The sex ratio of two groups were comparable to each other and statistically non significant. $(\mathrm{p}>0.05)$

Table 1: comparison of demographic data

\begin{tabular}{|l|c|c|c|}
\hline $\begin{array}{l}\text { Demographic } \\
\text { profile }\end{array}$ & Group B & Group R & P value \\
\hline Age(yrs) & $43.23 \pm 8.91$ & $40.97 \pm 9.98$ & 0.3 \\
\hline Weight(kgs) & $60.7 \pm 8.0$ & $67.2 \pm 10.6$ & 0.06 \\
\hline Gender(M/F) & $11 / 14$ & $13 / 12$ & 0.5 \\
\hline
\end{tabular}

Table 2: Type of surgery comparison between two groups

\begin{tabular}{|l|c|c|c|c|}
\hline Type of surgery & \multicolumn{2}{|c|}{ Group B } & \multicolumn{2}{c|}{ Group R } \\
\hline Lap hysterectomy & 08 & $32 \%$ & 09 & $36 \%$ \\
\hline Lap hernioplasty & 09 & $36 \%$ & 08 & $32 \%$ \\
\hline Lap hemicolectomy & 06 & $24 \%$ & 07 & $28 \%$ \\
\hline Lap AR & 02 & $8 \%$ & 01 & $4 \%$ \\
\hline
\end{tabular}

We conducted the study in 4 types of lower abdominal surgeries i.e. total laparoscopic hysterectomy, laparoscopic anterior resection, laparoscopic hemicolectomy and laparoscopic bilateral hernioplasty

Pain Scores was assessed with VAS at 30mins, $1 \mathrm{hr}$, $3 \mathrm{hrs}, 6 \mathrm{hrs}, 12 \mathrm{hrs}$, and $24 \mathrm{hrs}$ post extubation.

Table 3: Group comparison for VAS score

\begin{tabular}{|l|c|c|c|}
\hline $\begin{array}{l}\text { VAS after } \\
\text { extubation }\end{array}$ & Group B & Group R & P value \\
\hline 30MIN & $1.12 \pm 1.48$ & $1 \pm 1.11$ & 0.33 \\
\hline 1HR & $1.8 \pm 1.38$ & $1.6 \pm 1.22$ & 0.21 \\
\hline 3HRS & $2.48 \pm 0.96$ & $2.28 \pm 1.11$ & 0.24 \\
\hline 6HRS & $4.08 \pm 1.49$ & $2.7 \pm 0.79$ & $<0.001$ \\
\hline 12HRS & $3.36 \pm 0.66$ & $4 \pm 2.5$ & 0.03 \\
\hline 24HRS & $3.92 \pm 1.49$ & $3.92 \pm 0.91$ & 0.50 \\
\hline
\end{tabular}

VAS was not statistically significant at $30 \mathrm{mins}, 1 \mathrm{hr}$, $3 \mathrm{hrs}$ and $24 \mathrm{hrs}$ but statistically significant at $6 \mathrm{hrs}$, and $12 \mathrm{hrs}$.

Table 4: Comparison of mean duration of analgesia:

\begin{tabular}{|l|c|c|c|}
\hline $\begin{array}{l}\text { Time for first } \\
\text { analgesic } \\
\text { requirement }\end{array}$ & Group B & Group R & P value \\
\cline { 2 - 4 } & $401.73 \pm 297.85$ & $747.5 \pm 394.7$ & $<0.00001$ \\
\hline
\end{tabular}

The mean duration of analgesia (mean \pm SD) were $410.73+297.85$ mins in group $\mathrm{B}$ and $747.5+$ 394.7mins in group $\mathrm{R}$. The difference was statistically highly significant in group $\mathrm{R}$ compared to group B (p value <0.001).

\section{Discussion}

Pain after laparoscopic abdominal surgeries is due to many causes, some of which include - abdominal wall distension and incision at the trocar site. Several modalities have been used to alleviate pain after surgery - like nonsteroidal anti-inflammatory drugs (NSAIDs) (including parecoxib/valdecoxib [10], ketoprofen ${ }^{[11]}$, paracetamol), opioids (both intravenous and patient controlled analgesia), infiltration of local anaesthetic (both before and after creation of pneumoperitoneum), thoracic epidural block ${ }^{[12]}$, multimodal analgesia ${ }^{[13]}$ (using opioids, NSAID and infiltration of local anaesthetic) and ultrasound guided TAP block.

Ultrasound guided transversus abdominis plane block has become an integral part of multimodal analgesia after abdominal surgeries. Various drugs such as ropivacaine ${ }^{[14]}$, bupivacaine ${ }^{[15]},{ }^{[5]}$ and levobupivacaine have been used in ultrasound guided TAP block. In posterior approach of TAP block, a local anaesthetic is injected in the neurofascial plane between internal oblique and the transversus abdominis muscles, in order to block the nerves of the abdominal wall - namely the T7-T12 intercostal nerves, ilioinguinal nerve, iliohypogastric nerve and the lateral cutaneous branches of dorsal rami of the L1-L3 spinal nerves. [16]

Performance of TAP block has become an integral part of the multimodal regimen for providing postoperative analgesia in number of surgeries. In addition to providing real time visualization of the neural structures, use of ultrasound helps in delineating trajectory of needle and navigating it away from other anatomical structures. Thus it avoids intravascular and intraneuronal injection.

The present study showed that when administered via ultrasound guided TAP block with ropivacaine $(0.5 \%)$ provided more effective pain relief in the immediate post-operative period as compared to bupivacaine $(0.25 \%)$. The findings are in synchrony 
with the previous studies, which found ropivacaine to be more effective than bupivacaine. ${ }^{[17],[18],[19]}$

\section{Demographic Data}

The difference in the mean age (mean \pm SD) $43.23 \pm 8.91$ and $40.97 \pm 9.98$ years, body weight $60.7 \pm 8.0$ and $67.2 \pm 10.6 \mathrm{kgs}$ and sex ratio $11: 14$ and 13:12 of the patients in B group and R group were statistically not significant $(\mathrm{p}>0.05)$.Thus showing that baseline characteristics were comparable among the groups.

\section{Type of Surgery}

In the present study, we chose patients undergoing four types of lower abdominal surgeries which included total laparoscopic hysterectomy, laparoscopic anterior resection (LAR), laparoscopic hemicolectomy (LHC) and laparoscopic bilateral inguinal hernia (LIH). In B group 8 underwent TLH (32\%), 2 underwent LAR (8\%), 6 underwent LHC (24\%) and 9 underwent $\mathrm{LIH}(36 \%)$ whereas in R group 9 underwent TLH (36\%), 1 underwent LAR (4\%), 7 underwent LHC (28\%) and 8 underwent LIH (32\%).

Mark $\mathbf{J}$ Young et $\mathrm{al}^{[16]}$ described TAP block as an effective component of multimodal postoperative analgesia for a wide variety of abdominal procedures including large bowel resection, open/laparoscopic appendectomy, cesarean section, total abdominal hysterectomy, laparoscopic cholecystectomy, open prostatectomy, renal transplant surgery, abdominoplasty with/without flank liposuction, and iliac crest bone graft .

\section{Hemodynamic Variations}

In the present study, preoperative hemodynamics (mean \pm SD) - pulse rate ( per min) (group B 78.24 +9.24 vs. group R $73.84+6.88)$ and mean arterial pressure (group B $77.56+11.03$ vs. group R 75.52 +7.17 ) were comparable between the groups and statistically non significant. ( $>>0.05)$

The mean heart rate per min at $30 \mathrm{~min}, 1$ hour, 3 hours, 6hours, 12hours, and 24 hours in the postoperative period were compared between $0.25 \%$ bupivacaine and $0.5 \%$ ropivacaine. The results of both the studies were comparable at $30 \mathrm{~min}, 1 \mathrm{hr}$ and $3 \mathrm{hrs}$ but statistically significant difference was seen at $6 \mathrm{hrs}$ (group B $81.76 \pm 8.35$ vs. group R $78.76 \pm 4.94$ ), $12 \mathrm{hrs}$ ( group B $81.36 \pm 10.14$ vs. group R 79.48 \pm 4.36 ) and $24 \mathrm{hrs}$ (group B $80.68 \pm 11.87$ vs. group R 78.76 \pm 4.03 ).

The relative rise in pulse rate in Group B could possibly be explained because of the shorter duration and reduced efficacy of analgesia in the bupivacaine group as compared to the ropivacaine group The mean arterial pressure in $\mathrm{mm}$ of $\mathrm{Hg}$ (mean $\pm \mathrm{SD}$ ) at 30mins, 1 hour, 3 hours, 6hours, 12 hours, and 24 hours in postoperative period was also compared between $0.25 \%$ Bupivacaine and $0.5 \%$ Ropivacaine groups .The mean arterial pressure in both the groups were comparable and showed no significant difference.

This is similar to findings by Dr. Dipika patel et al [19] who compared $0.25 \%$ bupivacaine and $0.5 \%$ ropivacaine for TAP block in lower abdominal surgeries. They found that at 6,12 and 18 hours, there was a significantly low pulse rate and low blood pressure in Group R compared to Group B $(p<0.05)$. This difference was attributed to a relative rise in pulse and systolic blood pressure in Group B because a longer duration of analgesia was maintained in Group R.

Neha fuladi et $\mathrm{al}^{[17]}$ who also compared $0.25 \%$ bupivacaine and $0.5 \%$ ropivacaine, found that the difference between the mean pulse rate and mean systolic and diastolic blood pressure were statistically non-significant between group B and group $\mathrm{R}$ at all periods of time in the first $24 \mathrm{hrs}$.

\section{VAS Pain Score}

In the present study, the mean postoperative VAS in group B $(0.25 \%$ Bupivacaine) was maximum at the end of $6 \mathrm{hrs}$ whereas the mean postoperative VAS in group R (0.5\% Ropivacaine) was more at the end of $12 \mathrm{hrs}$. VAS score were not only lower in patients receiving $0.5 \%$ Ropivacaine but also statistically significant at $6 \mathrm{hrs}$ (group B $4.08 \pm 1.49$ vs. group R $2.7 \pm 0.79)$.

At $12 \mathrm{hrs}$ (group B $3.36 \pm 0.66$ vs. group R $4 \pm 2.5$ ) the Ropivacaine group had significantly more pain 
when compared to the Bupivacaine group. This was because group B had already received rescue analgesia.

Neha Sharma et al ${ }^{[18]}$ conducted a study in 60 adult patients undergoing elective abdominal surgery under general anaesthesia. They compared $0.25 \%$ Bupivacaine with $0.5 \%$ Ropivacaine in TAP block. The mean pain scores at $0 \mathrm{~min}, 30 \mathrm{~min}$ and $4 \mathrm{~h}$ were similar in both the groups and inter group comparison was not statistically significant. However, comparison of pain score at $8 \mathrm{~h}$ and $12 \mathrm{~h}$ post operatively showed significant difference in both the groups with Bupivacaine having significantly higher VAS scores both at rest and on coughing.

Dipika patel et al ${ }^{[19]}$ found that there was statistically significant difference in VAS score at 6 hours $(p<0.05)$ and 12 hours $(p<0.01)$ after performing the block. They found that VAS scores were higher in the Bupivacaine group as compared to the Ropivacaine group.

\section{Duration of Analgesia}

The mean time to first request for rescue analgesia in patients receiving $0.25 \%$ Bupivacaine was $410.73 \pm 297.85 \mathrm{mins}$ and $747.5 \pm 394.7 \mathrm{mins}$ in patients receiving $0.5 \%$ Ropivacaine. It indicates that mean duration of analgesia with $0.5 \%$ ropivacaine (approximately 12.5hrs) was significantly higher than $0.25 \%$ bupivacaine (approximately 6hrs). This finding is similar to that of other studies.

Dipika Patel et $\mathrm{al}^{[19]}$ who compared $0.25 \%$ bupivacaine with $0.5 \%$ ropivacaine found that the mean duration of analgesia was $7.38 \pm 2.35$ hours in bupivacaine group and $9.98 \pm 2.38$ hours in ropivacaine group. The difference was statistically highly significant in ropivacaine group compared to bupivacaine group $(\mathrm{p}<0.01)$.

Neha Fuladi et a ${ }^{[17]}$ found that the mean duration of analgesia in their study was longer in Ropivacaine group (12.61 \pm 5.13 hour) as compared to Bupivacaine group $(9.92 \pm 4.81)$ by $2.69 \pm 0.52$ hours, which was statistically significant.
All studies therefore showed ropivacaine to have better analgesic potency as well as longer duration of analgesia following TAP block.

\section{Timing of Request for Rescue Dose}

In $0.25 \%$ bupivacaine group, majority of patients (14 out of 25) received first dose of rescue analgesic between $6 \mathrm{hrs}$ to $12 \mathrm{hrs}$. In $0.5 \%$ ropivacaine group, majority of patients (13 out of 25) received first dose of rescue analgesic between $12 \mathrm{hrs}$ to $24 \mathrm{hrs}$. These results suggest that $0.5 \%$ ropivacaine provided longer duration of analgesia in majority of patients when compared to $0.25 \%$ bupivacaine. This also explains the mean duration of analgesia in $0.25 \%$ bupivacaine as $410.73+297.85 \mathrm{mins}$ and in $0.5 \%$ ropivacaine as $747.5+394.7 \mathrm{mins}$. In our study out of 50 patients, 2 patients from $0.25 \%$ bupivacaine group and 5 patients from $0.5 \%$ ropivacaine group did not request for rescue analgesia in first $24 \mathrm{hrs}$.

El Dawlatley et al $^{[20]}$ studied the analgesia of USG guided TAP block following laparoscopic cholecystectomy and reported reduced rescue analgesic requirement.

Gildasio S. De Oliveira ${ }^{[14]}$ compared postoperative opioid requirement in patients undergoing laparoscopic surgery who received TAP blocks with $0.25 \%$ ropivacaine, $0.5 \%$ Ropivacaine or saline. There was significant reduction in opioid consumption in the Ropivacaine groups as compared to saline group. However the opioid requirement was comparable between the $0.25 \%$ Ropivacaine and $0.5 \%$ Ropivacaine.

\section{Conclusions}

$0.5 \%$ Ropivacaine when compared with $0.25 \%$ Bupivacaine provides a longer duration of analgesia and potent analgesic efficacy in ultrasound guided TAP block. Thus, it is concluded that Ropivacaine can be used as a safe alternative to Bupivacaine, routinely for TAP block for patients undergoing abdominal surgeries. 


\section{References}

1. Peripheral I, Be a, Know B. Anatomy and Physiology. Pain. 2005;1-4.

2. Aveline C, Le Hetet H, Le Roux A, Vautier $\mathrm{P}$, Cognet F, Vinet E, et al. Comparison between ultrasound-guided transversus abdominis plane and conventional ilioinguinal/ iliohypogastric nerve blocks for day-case open inguinal hernia repair. $\mathrm{Br} \mathrm{J}$ Anaesth. 2011;106(3):380-6.

3. Clinical Anesthesiology [Internet]. 2014.

4. Kuppuvelumani P, Jaradi H, Delilkan A. Abdominal Nerve Blockade For Postoperative Analgesia After Caesarean Section. Asia Ocean J Obs Gynaecol 1993;19.

5. Niraj $G$, Searle A, Mathews M, Misra $V$, Baban M, Kiani S, et al. Analgesic efficacy of ultrasound-guided transversus abdominis plane block in patients undergoing open appendicectomy. $\mathrm{Br} \quad J \quad$ Anaesth. 2009;103(4):601-5.

6. McDonnell JG, Curley G, Carney J, Benton A, Costello J, Maharaj $\mathrm{CH}$, et al. The analgesic efficacy of transversus abdominis plane block after cesarean delivery: A randomized controlled trial. Anesth Analg. 2008;106(1):186-91.

7. Louis S. , N. M. 2007;35(4).

8. Tripathi KD. chapter 26: Local anaesthetics. 6/e. New Delhi: Jaypee brothers; 2008. 339$349 p$.

9. Lee A, Fagan D, Lamont M, Tucker GT, Halldin M, Scott DB. Disposition Kinetics of Ropivacaine in Humans [Internet]. Vol. 69, Anesthesia \& Analgesia. 1989.

10. Joshi, P. G, Viscusi, R. E, Gan, J. T, et al . Effectivetreatment of laparoscopic cholecystectomy pain with intravenous followed by oral COX-2 specific inhibitor Vol. 98, Anesthesia \& Analgesia. 2004.p.336-42.

11. Boccara G, Chaumeron A, Pouzeratte Y, Mann C. The preoperative administration of ketoprofen improves analgesia after laparoscopic cholecystectomy in comparison with propacetamol or postoperative ketoprofen. BJA $\mathrm{Br}$ J Anaesth 2005; 94(3):347.

12. Fujii Y, Toyooka H, Tanaka H. Efficacy of thoracic epidural analgesia following laparoscopic cholecystectomy. Eur J Anaesthesiol [Internet]. 1998 May [cited 2017 Jun 8];15(3):342-4.

13. Michaloliakou C, Chung F, Sharma S. Preoperative multimodal analgesia facilitates recovery after ambulatory laparoscopic cholecystectomy. Vol. 82, Anesthesia and analgesia. 1996. p. 44-51.

14. De Oliveira GS, Fitzgerald PC, Marcus RJ, Ahmad S, McCarthy RJ. A dose-ranging study of the effect of transversus abdominis block on postoperative quality of recovery and analgesia after outpatient laparoscopy. Anesth Analg.2011;113(5):1218-25.

15. Bharti N, Kumar P, Bala I, Gupta V. The efficacy of a novel approach to transversus abdominis plane block for postoperative analgesia after colorectal surgery. Anesth Analg. 2011;112(6):1504-8.

16. Young MJ, Gorlin AW, Modest VE, Quraishi SA Clinical implications of the transversus abdominis plane block in adults. Anesthesiol Res Pract. 2012;2012.

17. Fuladi N, Deshmukh S, Bhure A. Comparative Study of Bupivacaine $0.25 \%$ Versus Ropivacaine $0.5 \%$ in Transversus Abdominis Plane Block for Postoperative Analgesia in Lower Abdominal Surgeries : a Randomised Controlled Trial. J Evol Med Dent Sci [Internet]. 2014;3(17):4569-76. Available from: http://www.jemds.com/data_pdf/neha fuladi.pdf

18. Sharma N, Mehta N, Sharma S. An evaluation of $(0.25 \%)$ Bupivacaine Vs $(0.5 \%)$ Ropivacaine for postoperative analgesia using ultrasound guidedtransversus abdominis plane block for abdominal 
surgeries: A comparative study. Indian J Clin Anaesth. 2016;3(4):635-9.

19. Patel D, Patel B, Patel H, Shah D, Vachhrajani P.Transversus Abdominis Plane Block for Post Operative Analgesia in Lower Abdominal Surgery: A Comparison of Bupivacaine and Ropivacain. 2016;5 (12):446-50.

20. El-Dawlatly AA, Turkistani A, Kettner SC, Machata AM, Delvi MB, Thallaj A, et al. Ultrasound-guided transversus abdominis plane block:description of a new technique and comparison with conventional systemic analgesia during laparoscopic cholecystectomy. Br J Anaesth [Internet]. $2009 ; 102$. 